Queer Eye for the Straight Guy

Authors:

Dr Liz Morrish

Dept. English and Media Studies

Nottingham Trent University

Clifton

Nottingham

NG11 8NS

U.K.

and

Dr Kathleen O’Mara

Dept. Africana and Latino Studies

State University of New York

Oneonta, NY

13820

U.S.A. 


\section{Biographical Statements}

Dr Liz Morrish is Subject Leader of Linguistics at Nottingham Trent University. She is interested in the discursive negotiation of lesbian and gay sexual identity, the language of outing and the intersections of Linguistics and Queer Theory.

Dr Kathleen O’Mara is Chair of the Africana \& Latino Studies Department and affiliated with the departments of History and Women's \& Gender Studies at the State University of New York at Oneonta. Her recent research has focused on youth: the performance of sexual identity by queer youth of color, and the negotiation of social identity by Somali refugees. 


\section{Queer Eye for the Straight Guy}

\section{Introduction}

Queer Eye for the Straight Guy was a new take on the reality/makeover show which drew large audiences in the US during the rainy summer of 2003. A predictable media controversy followed mere visibility of gay men on national television. However, at no point in any of the shows is either heterosexuality or masculinity under assault. Rather, as we will argue in this essay, the reverse.

Each episode shows five gay men (the Fab Five) darting, Mission Impossible style, to the rescue of some, middle-class straight man, aged from his mid-twenties to early forties. The emergency is created by the subject's life of impaired taste, poor organization and slovenliness. The Fab Five resolve to rebuild him from components which together the cast provides, namely grooming, culture, interior design, fashion and food. The subjects' apartments are tidied, sanitized, sorted and the gay men perform fashion triage while coaching their novice towards some romantic denouement such as a proposal of marriage, a 'big boy date' or a dinner party to impress the woman he admires. The five sit around with wine observing this finale via CCTV link as their charge, newly emboldened, woos his lover.

Although many of the essentials of makeover shows like British television’s Life Laundry and How Clean is Your House? are present, there is none of the usual censoriousness or authoritarianism. The gay men in Queer Eye are humorous, sarcastic, but also indulgent and patient with their charges, and the whole show functions as a carnivalesque assault on traditional assumptions about masculinity and sexuality, while operating superficially with a set of comforting stereotypes about gay 
men. This essay outlines the way in which the text imparts these presumptions and then subverts, inverts and confounds them.

\section{Confirming and subverting the stereotypes}

Throughout each show there are both linguistic and paralinguistic performances of gay male identity; its juxtaposition with a rather blundering straight masculinity reinforces the former, and also allows a more sophisticated performance of alternative masculinity to emerge in the case of the straight male case study in each episode. At the beginning of each show, the Fab Five are shown clowning around the apartment of their bemused and disoriented straight subject. They swarm flamboyantly over his (and his wife/girlfriend's) most intimate possessions, shrieking at the fashion violations or abhorrent décor choices. The straight men are, without exception, slobs. We are privy to hairballs under the sofa cushions, bathtubs which require a paint scraper; as Ted remarks, "all the culture in the house is in the refrigerator or on the shower curtain.”

Gay identity is performed by means of the citational gender transgressions envisaged by Judith Butler. We hear swooping pitch ranges and the wide intonation contours of men whose self-expression is unencumbered by the precepts of hegemonic masculinity. Carson flirts amiably and continuously with all of his disciples, but while all of the Fab Five can camp it up for the opening and denouement scenes, the others are essentially straight-acting romantics, eschewing risqué comments (Kyan, Jai , Ted and Thom, though in a couple shows Blair substitutes for Jai). Many of the discourse choices are congruent with gay male identity: clothing is 'couture', “this place is tragic”, declaims Jai, while Carson announces: "we're going to show you the way of the gay”. And of course the show 
does presuppose that gay men are the arbiters of good taste; the Fab Five are superbly dressed and confident gay men. They care about domestic detail - color schemes, furniture, the thread count of their linens etc. But in fact, most of what they supply is rather obvious and accessible knowledge: how to shave, spray cologne, barbecue lamb, coordinate towels, get a manicure, use leaf tea for flavor, black and white coordinated clothing for elegance.

“The way of the gay” turns out to refer exclusively to a middle class style and domestic aptitude, because at all times the straight man's choice of object of desire is acknowledged. Some of the men, we learn almost incidentally, are actually married or live with women who are portrayed as the inspiration for the makeover, but remain in the rear view mirror until the denouement - this is a show about male bonding. And here another convention is endorsed: men will only pay attention to the opinions and prescriptions of other men. We must assume then, that the consort's chidings have been disregarded, and she has been obliged to summon an unconventional form of patriarchal supremacy. The straight female contingent of the show's audience must wonder how they might also supercede male intransigence.

The stereotype most cheerfully demonstrated by Queer Eye is that gay men are obsessed with sex. Carson is the most lethally witty and lasciviously-minded, but like the others, he observes boundaries occasioned by the slight awkwardness of the gaystraight culture clash. Noticing the headboard mirrors in the bedroom, he chants, "mirror, mirror on the wall, am I big or am I small? And recommending to an African American man, he declaims, “clean white underwear - it’ll make your skin pop....and maybe something else!” Occasionally Carson pushes the comfort levels of some of the straight men but it is through the device of humor and queenly ridicule that Carson constructs gay identity and deconstructs the uncontested certainties of straight 
masculinity. He expresses mock surprise when one subject confesses, that, no - he doesn't have a complete inventory of his couture, nor does he take polaroids of all his outfits, to avoid repetition in a 30 day period. He casts derision at straight men's inattentiveness to excess back hair, by remarking, “people will think it’s angora”, and booking the unfortunate into a waxing parlor.

In an apparent refutation of declared straight male norms, we see that Queer Eye's subjects can be comfortable with five exhilaratingly gay men, appreciate their difference and respect their opinions. At least, by the end, if not initially. Very few seem discomforted by openly affectionate gay men, swarming around their apartments, parading in their girlfriends' clothes. Just a few anxieties are voiced. One man asks a playful Carson “did you put the gay on me?” while another quizzes, “what are they doing back at my apartment?” Ted answers, “They’ve probably loaded up a spray gun and painted the whole place pink”.

But the straight men are at their most relaxed and confident at the finale. In the most profound inversion of assumptions we learn that gay men can construct conventional masculinity better than straight men. Their charges are not dragged up or feminized - they are 'manscaped'. As well as new slenderizing 'couture', the men have haircuts, manicures, waxes, spas, shaves and moisture treatments. And they cut better masculine figures as a result. The five gay men, paradoxically can make a straight man feel more confident in his masculinity and heterosexuality. And the women, inevitably, love the finished project, giving us yet another set of contradictions: gay men know the secrets of pleasing women better than straight men, and straight men want to please women in their dress, décor and provision of food. The underlying problematic of the show is that that all heterosexual women are presumed uniform in their preferences regarding "their" men, and all those featured 
are obligingly euphoric in their reactions. With women present and to be courted, the straight men's performance of masculinity is markedly different, now that it can be liberated from its function of performing difference from gay males. The Fab Five realize this: "look how relaxed he is, none of that guido mumble, the way he was with us” they remark about one man whose Stallone-like brevity has irked them throughout the day. "I haven’t seen a cop with such personality since Angie Dickinson,” twitters Carson acerbically.

\section{Conclusion}

This paper has discussed the contradictions, subversions and stereotypes brought into focus by Queer Eye. What makes this show different from others of its genre, and more entertaining, is the transgression and subversion of norms associated with gender and sexual identity. Masculinity, heterosexuality and homosexuality are constructed and deconstructed with humor and ridicule. While there is a degree of linguistic and paralinguistic congruity with gay stereotypes, the Fab Five do not all perform gay male identity in the same way. And yet the show's success is premised on the emergence of an authentic gay brand from amidst a plethora of masculinities. One joy of this show is its ability to challenge the idea of a hegemonic masculinity by allowing different variations to proliferate even within gay male identity. Is this what makes it truly Queer? And are lesbians ready for "Dyke D.I.Y. for the Straight Girl” on our screens sometime soon? 